\title{
Photoinduced $H S$ state in the first spin-crossover chain containing a cyanocarbanion as bridging ligand $\dagger$
}

\author{
Gaelle Dupouy, ${ }^{a}$ Mathieu Marchivie, ${ }^{a}$ Smail Triki, ${ }^{* a}$ Jean Sala-Pala, ${ }^{a}$ \\ Carlos J. Gómez-García, ${ }^{b}$ Sébastien Pillet, $^{c}$ Claude Lecomte $^{c}$ and Jean-François Létard ${ }^{d}$
}

Received (in Cambridge, UK) 3rd February 2009, Accepted 27th March 2009

First published as an Advance Article on the web 29th April 2009

DOI: $10.1039 / \mathbf{b} 902339 a$

\begin{abstract}
A new polymeric approach, based on cyanocarbanion ligands, for the design of spin crossover (SCO) compounds led us to the compound $\left[\mathrm{Fe}(\mathrm{abpt})_{2}(\mathrm{tcpd})\right](1)\left(\mathrm{tcpd}^{2-}=\left(\mathrm{C}\left[\mathrm{C}(\mathrm{CN})_{2}\right]_{3}\right)^{2-}\right.$, abpt $=$ 4-amino-3,5-bis(pyridin-2-yl)-1,2,4-triazole) which has been characterised as the first SCO molecular chain involving a cyanocarbanion as bridging ligand.
\end{abstract}

The design of new molecular compounds exhibiting the spin crossover phenomenon (SCO) is one of the most relevant and challenging questions in the field of magnetic molecular materials. ${ }^{1-4}$ Iron(II) metal complexes involving the octahedral coordination sphere $\left[\mathrm{FeN}_{6}\right]$ are the most studied SCO compounds. In such materials, the intermolecular interactions ( $\pi$-stacking, hydrogen bonding and van der Waals interactions) play a crucial role to transmit the transition. ${ }^{5}$ Albeit, the lack of control of these non-covalent interactions hardens their organization in the crystal. To better explore the cooperative effect between the active metal sites, Kahn et al., ${ }^{2}$ and others, ${ }^{3,4}$ introduced an interesting and alternative approach based on the use of neutral suitable bridging ligands to covalently connect the metal centres. This resulted in the synthesis of several $\mathrm{Fe}^{\mathrm{II}} \mathrm{SCO}$ coordination polymers exhibiting rich and fascinating structural features coupled to their magnetic behaviours. However, these studies concern a limited number of neutral ligands and deal essentially with 4-substituted-1,2,4-triazole and poly-N-donating heterocyclic ligands. ${ }^{2-4}$ In this context, our strategy is to extend this polymeric approach to anionic ligands involving several potentially donating nitrogen atoms (Scheme 1).

In our ongoing work on the new potentially bridging cyanocarbanion ligands, we have shown in the last few years that their structural and electronic characteristics (original coordination modes and high electronic delocalization) can be tuned by slight chemical or electrochemical modifications such as substitution of functional groups or variation of the

${ }^{a}$ UMR CNRS 6521, Université de Bretagne Occidentale, BP 809, 29285, Brest Cedex, France.E-mail:triki@univ-brest.fr; Fax: + 33 298017001; Tel: + 33298016146

${ }^{b}$ Instituto de Ciencia Molecular. Parque Cientifico. Universidad de Valencia, Paterna, 46980, Valencia, Spain

${ }^{c}$ LCM3B, Nancy-Université, CNRS, Boulevard des Aiguillettes,

B.P. 239, 54506, Nancy, France

'ICMCB, CNRS, Université Bordeaux 1, 87 Av. Doc. A. Schweitzer, F-33608, Pessac, France

$\dagger$ Electronic supplementary information (ESI) available: Detailed synthesis, IR spectroscopy, further crystallographic details and magnetic properties. CCDC 705802-705805. For ESI and crystallographic data in CIF or other electronic format see DOI: 10.1039/b902339a negative charge. ${ }^{6}$ In this context, we have directed our efforts to the preparation of new SCO polymeric systems based on such bridging anions, for which the magnetic properties are essentially governed by subtle structural changes and therefore by the nature of the cyanocarbanion ligand.

Recently we have reported the first SCO series based on the $\mathrm{tcm}^{-}\left(\left[\mathrm{C}(\mathrm{CN})_{3}\right]^{-}\right)$, tcnome ${ }^{-}$and tcnoet $^{-}$ligands and abpt co-ligand (Scheme 1). ${ }^{5}$ In this series, the single charge on the anion induces a terminal coordination mode for the polynitrile unit, resulting in neutral discrete SCO complexes. A further step in this direction would be the preparation of original extended SCO networks bearing the $\mathrm{Fe}^{\mathrm{II}}$-abpt complexes by using covalent bonds. Here we show how the use of potentially bridging dianionic ligands bearing different coordination sites constitute a very good and simple method to perform this task. We report herein the first SCO iron(II) molecular neutral chain $\left[\mathrm{Fe}(\mathrm{abpt})_{2}(\mathrm{tcpd})\right](\mathbf{1})$ involving an anion as bridging ligand. To the best of our knowledge, only two SCO molecular chains involving bridging anions have been reported. The first one, based on the triazolato anion, has not been fully structurally characterized, ${ }^{7 a}$ the second one is based on dicyanamide anion (aza-cyanocarbanion). ${ }^{7 b}$

Compound 1 was obtained by diffusion of a methanolic solution containing $\mathrm{FeCl}_{2} \cdot 4 \mathrm{H}_{2} \mathrm{O}$ and abpt in an aqueous solution of $\mathrm{K}_{2}(\mathrm{tcpd})^{8}$ in a silica gel (see $\mathrm{S} 1$ in $\mathrm{ESI} \dagger$ ). Single-crystal X-ray diffraction data of $\mathbf{1}$ were collected at 293,100 and $10 \mathrm{~K}$ (flash cooled and light induced states). $\ddagger$ The structure of 1 is built from one iron $\mathrm{Fe}^{\mathrm{II}}$ ion, one tcpd ${ }^{2-}$ anion presenting an orientation disorder (both located on inversion centers) and one chelating abpt ligand located on a general position. As shown in Fig. 1, the $\mathrm{Fe}^{\mathrm{II}}$ ion adopts a $\mathrm{FeN}_{4} \mathrm{~N}_{2}$ distorted octahedral geometry with four equatorial nitrogen atoms from two abpt chelating ligands (N1, N2, N1 ${ }^{(a)}$ and $\mathrm{N} 2^{(\mathrm{a})}$ ) and two axial nitrogen atoms (N3 and $\mathrm{N} 3^{(\mathrm{a})}$ ) from the $\operatorname{tcpd}^{2-}$ ligand. The cyanocarbanion ligand adopts a $\mu_{2}$-bridging mode via two nitrogen atoms of two different $\mathrm{C}(\mathrm{CN})_{2}$ wings leading to a chain structure as depicted in Fig. 1. It is important to note that the disordered tcpd ${ }^{2-}$ bridging ligand implies a more complicated local structure.

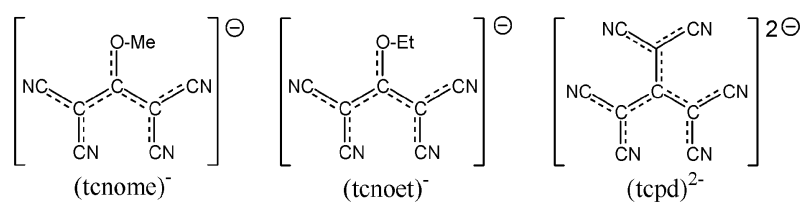

Scheme 1 Some examples of cyanocabanions. 


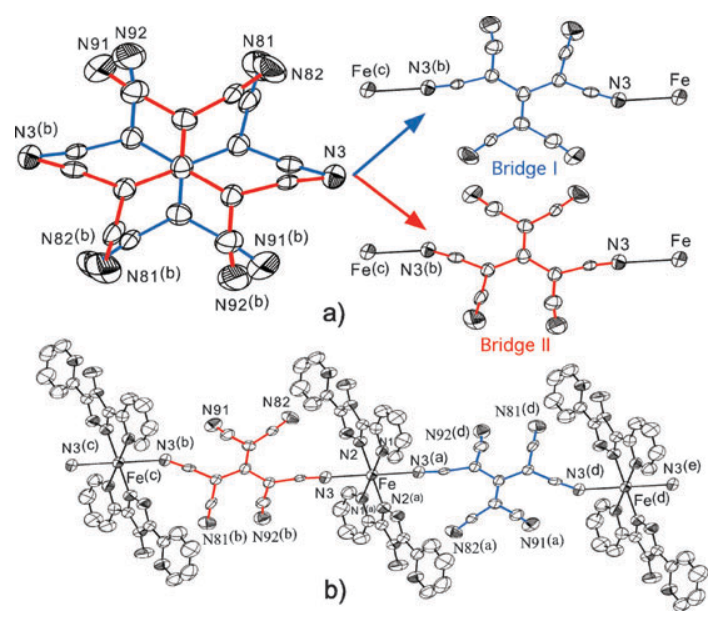

Fig. 1 (a) ORTEP structure of the disordered bridging tcpd ${ }^{2-}$ anion; (b) ORTEP perspective view of a possible portion of the 1-D structure of 1 at $293 \mathrm{~K}$. Code of equivalent positions: (a) $1-x, 2-y,-z$; (b) $2-x, 2-y,-z$; (c) $1+x, y, z$; (d) $-1+x, y, z$; (e) $-x, 2-y,-z$.

Thus, the overall crystal structure may be pictured as formed by chains presenting statistically two different orientations of the $\operatorname{tcpd}^{2-}$ ligand as shown in Fig. 1(a) (see also Fig. S2 in ESI $\dagger$ ). This observation is in good agreement with the crystallographic data since all attempts to solve the crystal structure in the corresponding non-centrosymmetric space group $\left(P n, P 2_{1}\right.$ and $\left.P 1\right)$ failed.

As can be seen in Table 1, strong modifications of the iron coordination sphere are observed in the temperature range 293-10 K. Such behaviour is in agreement with the presence of a SCO transition from $H S$ to $L S$ in 1 . The average $\mathrm{Fe}-\mathrm{N}$ distances at room temperature and at $10 \mathrm{~K}$ "flash cooled" are in the range expected for $100 \%$ and $50 \%$ of the $H S$ iron(II), respectively. ${ }^{9}$ This observation is consistent with the presence of a metastable $H S$ state at low temperatures as magnetic data indicate only ca. $30 \%$ remaining $H S \mathrm{Fe}^{\mathrm{II}}$ at low temperature. Flash cooling results therefore in nearly $50 \%$ trapped $H S$ species. When a single crystal is irradiated at $10 \mathrm{~K}$, the average $\mathrm{Fe}-\mathrm{N}$ distance increases to $2.156(3) \AA$, very close to the corresponding value observed at room temperature (2.159(2) ^).

This unusual behaviour is the structural signature of the presence of a photo-induced $H S$ state in $\mathbf{1}$, in agreement with the magnetic properties of this complex (see below).

The thermal dependence of the product of the molar magnetic susceptibility and the temperature $\left(\chi_{\mathrm{m}} T\right)$ for $\mathbf{1}$ shows a room-temperature value of $3.35 \mathrm{~cm}^{3} \mathrm{~K} \mathrm{~mol}^{-1}$ that remains constant down to $c a .170 \mathrm{~K}$ (Fig. 2). This value, slightly higher than the spin-only value calculated for an isolated metal ion

Table 1 Selected bond distances ( $\mathrm{A})$ for $\mathbf{1}$

\begin{tabular}{lllll}
\hline & & & \multicolumn{2}{l}{$T=10 \mathrm{~K}$} \\
\cline { 3 - 5 } & $T=293 \mathrm{~K}$ & $T=100 \mathrm{~K}$ & $\begin{array}{l}\text { Flash } \\
\text { cooled }\end{array}$ & $\begin{array}{l}\text { Light } \\
\text { induced }\end{array}$ \\
\hline Fe1-N1 & $2.187(2)$ & $2.114(2)$ & $2.091(3)$ & $2.179(3)$ \\
Fe1-N2 & $2.113(2)$ & $2.060(2)$ & $2.047(3)$ & $2.113(3)$ \\
Fe1-N3 & $2.176(2)$ & $2.075(2)$ & $2.056(3)$ & $2.175(3)$ \\
$<\mathrm{Fe}-\mathrm{N}>$ & $2.159(2)$ & $2.083(2)$ & $2.065(3)$ & $2.156(3)$ \\
\hline
\end{tabular}

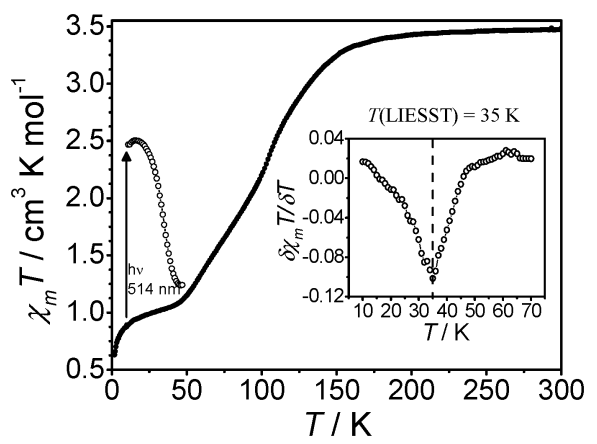

Fig. 2 Thermal variation of the $\chi_{\mathrm{m}} T$ product $(\bullet)$, light irradiation at $10 \mathrm{~K}(\lambda=514 \mathrm{~nm})$ and thermal variation of the $\chi_{\mathrm{m}} T$ product for 1 after irradiation $(\bigcirc)$. Inset: derivative of the thermal variation of the $\chi_{\mathrm{m}} T$ product on increasing temperature after irradiation showing the $T$ (LIESST) value.

with $S=2\left(3.0 \mathrm{~cm}^{3} \mathrm{~K} \mathrm{~mol}^{-1}\right)$, indicates that compound $\mathbf{1}$ is essentially paramagnetic and the $\mathrm{Fe}^{\mathrm{II}}$ ions present the high spin $(S=2)$ configuration in that temperature range.

Below $170 \mathrm{~K}$ the $\chi_{\mathrm{m}} T$ product decreases continuously down to $45 \mathrm{~K}$ and then reaches a plateau with a value close to $1.0 \mathrm{~cm}^{3} \mathrm{~K} \mathrm{~mol}^{-1}$. These features reveal an incomplete $H S-L S$ conversion of about $70 \%$. Below $10 \mathrm{~K}, \chi_{\mathrm{m}} T$ presents a sharp decrease to reach a value of $0.8 \mathrm{~cm}^{3} \mathrm{~K} \mathrm{~mol}^{-1}$ at $2 \mathrm{~K}$ that is probably due to the presence of a zero-field splitting in the remaining $H S$ molecules and/or to a weak antiferromagnetic coupling of the remaining $H S$ molecules. The heating scan shows an identical behaviour within the experimental error. Careful examination of the $\chi_{\mathrm{m}} T$ product in the temperature range $170-45 \mathrm{~K}$ reveals an unexpected thermal behaviour with a slight change in the slope around $100 \mathrm{~K}$ and maxima at ca. 60 and $105 \mathrm{~K}$ in the derivative of $\chi_{\mathrm{m}} T$ (Fig. S3A, ESI $\dagger$ ). This observation is in agreement with the crystal structure of $\mathbf{1}$ since the two statistical orientations of the tcpd ${ }^{2-}$ ligand (see crystal structure description) imply at least two $\mathrm{Fe}^{\mathrm{II}}$ environments. Such atypical feature may be explained by the contraction, just below $170 \mathrm{~K}$, of the $\mathrm{Fe}^{\mathrm{II}}$ coordination sphere due to the $H S-L S$ transition leading to an increase of the energy gap between $H S$ and $L S$ levels of one or two neighbouring $\mathrm{Fe}^{\mathrm{II}}$ ions along the chain. Such a phenomenon is somewhat similar to that observed for some $\mathrm{Fe}^{\mathrm{II}}$ dinuclear complexes and for the 1-D chain $\left[\mathrm{Fe}(\mathrm{NCSe})_{2}(\mathrm{bdpp})\right]$, for which their SCO transitions are of the two-step character. ${ }^{10,11}$ In the case of the title compound, the situation is much more complicated since its overall structure presents two statistically different orientations of the $\mathrm{tcpd}^{2-}$, and then the SCO transition may be viewed as a multi-step process operating statistically within the crystal. This assumption is emphasized by the presence of two statistically different orientations of the bridging $\mathrm{tcpd}^{2-}$ anion and by the incomplete $H S-L S$ conversion observed below 45 K. Fig. 2 also shows the photomagnetic properties performed with a SQUID magnetometer coupled to a mixed kryptonargon laser, using a reported standardised procedure. ${ }^{12}$ Irradiation at $10 \mathrm{~K}$ with green laser light $(\lambda=514 \mathrm{~nm}$, $5 \mathrm{~mW} \mathrm{~cm}^{-2}$ ) resulted in a large increase of the magnetic signal. After $1 \mathrm{~h}$ of irradiation, the light was switched off and the temperature increased at a rate of $0.3 \mathrm{~K} \mathrm{~min}^{-1}$, corresponding to the measurement of the $T$ (LIESST) temperature. ${ }^{12}$ Based 
on this experiment several remarks can be made. The small decrease of the magnetic signal recorded below $25 \mathrm{~K}$ can be attributed either to the zero-field splitting of the individual photo-induced $H S$ state and/or to a small antiferromagnetic coupling between the $\mathrm{Fe}^{\mathrm{II}} H S$ states in the 1-D chain, as reported with a larger magnitude for $\mathrm{Fe}^{\mathrm{II}}$ dinuclear complexes and for some chain complexes with the same bridging tcpd $^{2-}$ ligand. ${ }^{13}$ The comparison between the maxima of the $T$ (LIESST) curves and the magnetic value of the thermal high-spin state argues in favour with a photoconversion of about $70 \%$ in bulk material. Along these lines, upon increasing the intensity and/or changing the wavelength of excitation, it was not possible to reach a quantitative photo-excitation. As the colour of the sample is basically not so deep, a problem of penetration depth can be ruled out, this effect can rather be attributed to a competition between excitation and an efficient $H S-L S$ relaxation process, also illustrated by the relatively small $T$ (LIESST) temperature of $35 \mathrm{~K}$. The last comment concerns the trapped $H S$ state which relaxes back to the original thermal spin transition curve, rather than to a fully low-spin state. This confirms that the incompleteness of the spin-crossover in this compound may not be caused by kinetic trapping of a high-spin fraction of the sample at low temperatures, as was recently reported for the $\left[\mathrm{FeL}_{2}\right]\left[\mathrm{BF}_{4}\right]_{2} \cdot x \mathrm{H}_{2} \mathrm{O}$ complex $\left(\mathrm{L}=2,6\right.$-bis $\{3$-methylpyrazol-1-yl $\}$ pyridine; $\left.x=0-\frac{1}{3}\right) .{ }^{14}$ However, further studies such as solving the crystal structure at $10 \mathrm{~K}$ after slow cooling should provide more information about the origin of this residual $H S$ fraction.

In summary, we have reported the synthesis, structural characterisations and magnetic properties of the complex $\left[\mathrm{Fe}(\mathrm{abpt})_{2}\right.$ (tcpd)] (1) which is the first SCO neutral molecular chain containing a cyanocarbanion as bridging ligand. Magnetic and photomagnetic studies show a gradual $L S-H S$ conversion and photoinduced effects $\left(T_{\text {LIESST }}=35 \mathrm{~K}\right)$, in agreement with the crystallographic and photo-crystallographic results. In a synthetic perspective, this result confirms the ability of the cyanacarbanions to act as bridging ligands to generate new SCO complexes exhibiting original extended arrangements.

The authors acknowledge the CNRS, Brest and Nancy Universities, the Ministère de la Recherche (PPF "Cristallographie et Photocristallographie à haute résolution"), the European Union for financial support (COST Action D35-WG-0010-05/0011-05 and MAGMANet network of excellence) and the Spanish Ministerio de Educación y Ciencia (Projects MAT2007-61584 and CSD 2007-00010 Consolider-Ingenio in Molecular Nanoscience).

\section{Notes and references}

$\ddagger$ Crystal data for $1: \mathrm{C}_{34} \mathrm{H}_{20} \mathrm{~N}_{18} \mathrm{Fe}, M=736.53$, monoclinic, space group $P 2_{1} / n, Z=2, T=293 \mathrm{~K}:$ yellow; $a=11.3762(3)$, $b=12.4222(3), c=11.8683(3) \AA, \beta=92.031(2)^{\circ}, V=1676.14(7) \AA^{3}$, $D_{\mathrm{c}}=1.459 \mathrm{~g} \mathrm{~cm}^{-3}, 18122$ collected reflections, 2390 unique $\left(R_{\mathrm{int}}\right.$ $=0.0275$ ), final GOF $=1.112$ (all data), $R 1=0.0353, \mathrm{w} R 2=0.0747$, $R$ indices based on 1858 reflections with $I>2 \sigma(I), 333$ parameters. $T=100 \mathrm{~K}:$ red; $a=11.2359(3), b=12.2079(2), c=11.8655(2) \AA$, $\beta=91.703(2)^{\circ}, V=1626.83(6) \AA^{3}, D_{\mathrm{c}}=1.504 \mathrm{~g} \mathrm{~cm}^{-3}, 21459$ collected reflections, 3234 unique $\left(R_{\mathrm{int}}=0.0311\right)$, final GOF $=1.110$ (all data), $R 1=0.0417, \mathrm{w} R 2=0.0839, R$ indices based on 2353 reflections with $I>2 \sigma(I), 323$ parameters. $T=10 \mathrm{~K}$, "flash cooled": red; $a=11.2071(8), b=12.1518(6), c=11.8916(5) \AA$, $\beta=91.495(5)^{\circ}, V=1618.9(2) \AA^{3}, D_{\mathrm{c}}=1.511 \mathrm{~g} \mathrm{~cm}^{-3}, 7010$ collected reflections, 2474 unique $\left(R_{\text {int }}=0.0457\right)$, final GOF $=1.040$ (all data), $R 1=0.0485, \mathrm{w} R 2=0.0810, R$ indices based on 1514 reflections with $I>2 \sigma(I), 298$ parameters. $T=10 \mathrm{~K}$, light induced: yellow; $a=11.3894(8), b=12.1165(4), c=11.8384(4) \AA, \beta=92.832(4)^{\circ}$, $V=1631.70(14) \AA^{3}, D_{\mathrm{c}}=1.499 \mathrm{~g} \mathrm{~cm}^{-3}, 6258$ collected reflections, 2337 unique $\left(R_{\text {int }}=0.0267\right)$, final GOF $=1.144$ (all data), $R 1=0.0483, \mathrm{w} R 2=0.0892, R$ indices based on 1747 reflections with $I>2 \sigma(I), 289$ parameters (see S2 in $\mathrm{ESI} \dagger$ for details).

1 See, for general reviews: (a) Spin Crossover in Transition Metal Compounds, Topics in Current Chemistry, Springer Verlag, Berlin-Heidelberg-New York, 2004, vol. 233; (b) P. Gütlich, A. Hauser and H. Spiering, Angew. Chem., Int. Ed. Engl., 1994, 33, 2024; (c) S. Cobo, G. Molnár, J. A. Real and A. Bousseksou, Angew. Chem., Int. Ed., 2006, 45, 5786; (d) E. Coronado, J.-R. Galán-Mascarós, M. Monrabal-Capilla, J. García-Martínez and P. Pardo-Ibánez, Adv. Mater., 2007, 19, 1359.

2 (a) W. Vreugdenhil, J. H. van Diemen, R. A. G. de Graaff, J. G. Haasnoot, J. Reedjik, J. A. M. van der Kraan, O. Kahn and J. Zarembowitch, Polyhedron, 1990, 9, 2971; (b) O. Kahn and C. J. Martinez, Science, 1998, 279, 44; (c) Y. Garcia, O. Kahn, L. Rabardel, B. Chansou, L. Salmon and J.-P. Tuchagues, Inorg. Chem., 1999, 38, 4663.

3 (a) C. Genre, G. S. Matouzenko, E. Jeanneau and D. Luneau, New J. Chem., 2006, 30, 1669; (b) G. S. Matouzenko, G. Molnár, N. Bréfuel, M. Perrin, A. Bousseksou and S. A. Borshch, Chem. Mater., 2003, 15, 550; (c) G. S. Matouzenko, M. Perrin, B. Le Guennic, C. Genre, G. Molnár, A. Bousseksou and S. A. Borshch, Dalton Trans., 2007, 934.

4 (a) N. Moliner, M. C. Munoz, S. Létard, L. Salmon, J.-P. Tuchagues, A. Bousseksou and J. A. Real, Inorg. Chem., 2002, 41, 6997; (b) J. A. Real, E. Andrés, M. C. Munoz, M. Julve, T. Granier, A. Bousseksou and F. Varret, Science, 1995, 268, 265; (c) Y. Garcia, V. Niel, M. C. Munoz and J. A. Real, Top. Curr. Chem., 2004, 233, 229; (d) J. A. Real, A. B. Gaspar, V. Niel and M. C. Munoz, Coord. Chem. Rev., 2003, 236, 121; (e) K. S. Murray and C. J. Kepert, Top. Curr. Chem., 2004, 233, 195; (f) R. Bronisz, Inorg. Chem., 2005, 44, 4463.

5 G. Dupouy, M. Marchivie, S. Triki, J. Sala-Pala, J.-Y. Salaün, C. J. Gómez-García and P. Guionneau, Inorg. Chem., 2008, 47, 8921.

6 See, for example: (a) C. Atmani, F. Setifi, S. Benmansour, S. Triki, M. Marchivie, J.-Y. Salaün and C. J. Gómez-García, Inorg. Chem. Commun., 2008, 11, 921; (b) S. Triki, F. Thétiot, F. Vandevelde, J. Sala-Pala and C. J. Gómez-Garcia, Inorg. Chem., 2005, 44, 4086.

7 (a) J. G. Haasnoot, J. G. Vos and W. L. Groeneveld, Z. Naturforsch., B: Anorg. Chem. Org. Chem., 1977, 32, 1421; (b) C. Genre, E. Jeanneau, A. Bousseksou, D. Luneau, S. A. Borshch and G. S. Matouzenko, Chem.-Eur. J., 2008, 14, 697.

8 W. J. Middleton, E. L. Little, D. D. Coffman and V. A. Engelhardt, J. Am. Chem. Soc., 1958, 80, 2795.

9 P. Guionneau, M. Marchivie, G. Bravic, J.-F. Létard and D. Chasseau, Top. Curr. Chem., 2004, 234, 97.

10 (a) J. A. Real, H. Bolvin, A. Bousseksou, A. Dworkin, O. Kahn, F. Varret and J. Zarembowitch, J. Am. Chem. Soc., 1992, 114, 4650; (b) A. Bousseksou, G. Molnár, J. A. Real and K. Tanaka, Coord. Chem. Rev., 2007, 251, 1822; (c) N. Ould Moussa, S. Mouri, G. Molnár, K. Tanaka, J. A. Real and A. Bousseksou, J. Inorg. Organomet. Polym. Mater., 2008, 195.

11 S. M. Neville, B. A. Leita, G. J. Halder, C. J. Kepert, B. Moubaraki, J.-F. Létard and K. S. Murray, Chem.-Eur. J., 2008, 14, 10123.

12 (a) J.-F. Létard, P. Guionneau, O. Nguyen, J. S. Costa, S. Marcen, G. Chastanet, M. Marchivie and L. Goux-Capes, Chem.-Eur. J., 2005, 11, 4582; (b) J.-F. Létard, J. Mater. Chem., 2006, 16, 2550.

13 (a) J.-F. Létard, J. A. Real, N. Moliner, A. B. Gaspar, L. Capes, O. Cador and O. Kahn, J. Am. Chem. Soc., 1999, 121, 10630; (b) G. Chastanet, A. B. Gaspar, J. A. Real and J.-F. Létard, Chem. Commun., 2001, 819; (c) F. Thétiot, S. Triki, J. Sala-Pala and C. J. Gómez-García, Synth. Met., 2005, 153, 481; (d) S. Triki, F. Thétiot, F. Vandevelde, J. Sala-Pala and C. J. Gómez-García, Inorg. Chem., 2005, 44, 4086.

14 V. A. Money, C. Carbonera, M. A. Halcrow, J. A. K. Howard and J.-F. Létard, Chem.-Eur. J., 2007, 13, 5503. 